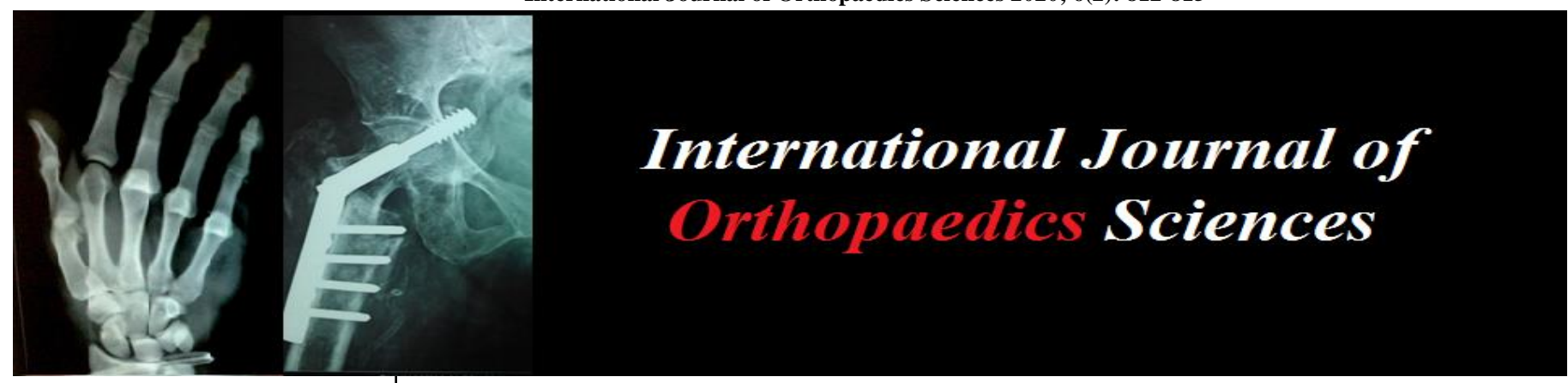

E-ISSN: 2395-1958

P-ISSN: 2706-6630

IJOS 2020; 6(2): 812-815

(C) 2020 IJOS

www.orthopaper.com

Received: 22-02-2020

Accepted: 24-03-2020

Dr. Vamshi Krishna Reddy Chilakamary

Assistant Professor

Department of Orthopaedics

Kamineni Institute of Medical

Sciences Narketpally, Nalgonda

Dist Telangana, India

Dr. Sukesh Sankineni

Consultant Orthopaedician

Yashoda Hospital Secunderabad,

Telangana, India
Corresponding Author: Dr. Vamshi Krishna Reddy Chilakamary

Assistant Professor Department of Orthopaedics Kamineni Institute of Medical Sciences Narketpally, Nalgonda Dist Telangana, India

\section{Effect of the knee position during wound closure after total knee arthroplasty on early knee function recovery: A prospective study}

\author{
Dr. Vamshi Krishna Reddy Chilakamary and Dr. Sukesh Sankineni
}

DOI: https://doi.org/10.22271/ortho.2020.v6.i2m.2143

\begin{abstract}
Introduction: The success of a TKR depends on various factors which include appropriate choice of implant and meticulous surgical technique. A simple soft-tissue tension in the anterior knee after TKA can cause knee pain and loss of ROM. Surgical technique significantly influences joint function recovery after TKA. Research mainly focuses on flexion and extension gap balance, rotational alignment and medial and lateral collateral ligament balance. The traditional knee wound closure in extension may lead to soft-tissue misalignment, resulting in higher soft-tissue tension of the anterior knee in flexion. This condition may lead to anterior knee pain and may limit postoperative ROM recovery.

Material and Methods: This study is a prospective randomised study of 6 months duration done in Sunshine Hospital, Secunderabad, Telangana A total of 66 patients from June 2016 to November 2016 were enrolled in this study. The patients were randomized according to the type of wound closure: Extension group for full extension and Flexion group for $90^{\circ}$ flexion. In the flexion group, the knee will be kept in high flexion for 1 to $2 \mathrm{~min}$ after wound closure. Age, gender, body mass index, ROM, visual analogue scale (VAS) pain score of anterior knee and Knee Society Score (KSS, American Society of Knee Surgery) were not significantly different between the two groups. Thus, extension group and flexion group were comparable.

Results: In post op evaluation VAS for anterior knee at $6^{\text {th }}$ wk follow up was found to be statistically significant (p-0.004) in favour of flexion group but at 3 month follow up the difference was not found to be statistically significant (p- 0.010).In post op ROM evaluation between two groups showed higher $\mathrm{ROM}$ at $6^{\text {th }}$ wk and $3^{\text {rd }}$ month which was statistically significant with $\mathrm{p}-0.001$ and 0.001 respectively. Knee society score was found to be statistically significant only at $3^{\text {rd }}$ month follow up between the groups, with better score in flexion group.

Conclusion: The knee position during wound closure after TKA is not only critical but also very important for postoperative knee function recovery. Wound closure in flexion can effectively decrease anterior knee pain after TKA and promote the early recovery of ROM. This difference is more pronounced in patients with BMI $>30$.Furher study has to be done for $6^{\text {th }}$ month and $1 \mathrm{yr}$ follow up evaluation to see whether these differences will persist.
\end{abstract}

Keywords: Total knee replacement, post TKR anterior knee pain, Post TKR ROM, closure in TKR

\section{Introduction}

The success of a TKR depends on various factors which include appropriate choice of implant and meticulous surgical technique. It is often said that a knee replacement is a soft tissue operation and balancing the soft tissues gives good outcomes. Mention must also be made of the concept of minimal soft tissue trauma surgery where gentle handling of the tissues during surgery helps in reduced wound complications. However many standard textbooks of knee arthroplasty do not dwell on the detail of closure. Incidence of anterior knee pain after primary TKA is from $10 \%$ to $15 \%{ }^{[1-3]}$.

A simple soft-tissue tension in the anterior knee after TKA can cause knee pain and loss of $\mathrm{ROM}^{4}$. Surgical technique significantly influences joint function recovery after TKA. Research mainly focuses on flexion and extension gap balance, rotational alignment and medial and lateral collateral ligament balance. The traditional knee wound closure in extension may lead to soft-tissue misalignment, resulting in higher soft-tissue tension of the anterior knee in flexion. This condition may lead to anterior knee pain and may limit postoperative 
ROM recovery ${ }^{[5]}$. Optimising knee range of motion following total knee arthroplasty (TKA) is important for patient satisfaction, functional outcome and early rehabilitation to promote accelerated discharge. Historically, wound closure following TKA has been performed in extension. It has been suggested that knee position during wound closure may influence range of motion and clinical outcomes following TKA. Traditionally, the surgical wound closure following a TKA has been performed with the patient supine and the knee in full extension.

However, some authors have suggested that closure of the knee in flexion may be advantageous. King et al. suggested that skin tightness, attributed to wound closure in terminal knee extension, may lead to increased post-operative pain and limit a patient's ability to regain his/her range of motion ${ }^{[6]}$. It was speculated that wound closure in extension could cause a relative shortening of the extensor mechanism and skin, which would contribute to increased discomfort compared to wound closure performed in flexion. As a consequence, King et al. suggested that TKA wounds should be closed in some degree of knee flexion ${ }^{[6]}$. The objective of this study is to investigate the effect of the knee position during wound closure on early knee function recovery after total knee arthroplasty (TKA).

\section{Material and Methods}

This study is a prospective randomised study of 6 months duration done in Sunshine Hospital, Secunderabad, Telangana A total of 66 patients from June 2016 to November 2016 were enrolled in this study. All patients had been treated with primary TKA for osteoarthritis.

The exclusion criteria were as follows: knee surgery history (femur or tibia osteotomy, knee arthroscopic surgery), patella fracture history, knee valgus $\left(>15^{\circ}\right.$, requiring lateral retinacular release) or fixed-flexion deformity, knee infection history and neuromuscular disorders affecting knee motion.

The patients were randomized according to the type of wound closure: Extension group for full extension and Flexion group for $90^{\circ}$ flexion. In the flexion group, the knee will be kept in high flexion for 1 to 2 min after wound closure. Age, gender, body mass index, ROM, visual analogue scale (VAS) pain score of anterior knee and Knee Society Score (KSS, American Society of Knee Surgery) were not significantly different between the two groups. Thus, extension group and flexion group were comparable.

After the completion of evaluation according to the enrolment and exclusion criteria, an informed consent was taken.

Surgical tecnnique: All patients were administered with Spinal anaesthesia and subjected to TKA through parapatellar medial approach by the same surgeon. The skin, patellar tendon and upper and lower patella poles with articular capsule incision were marked for precise soft-tissue alignment in closure. An equivalent bone cuts of femur and tibia were done, and the posterior knee osteophyte was removed. The tibia posterior slope was $3^{\circ}$, and Zimmer NK-2 prosthesis was implanted. After osteophyte removal, the patella was shaped using an electric pendulum saw without patellar resurfacing. Prior to skin incision, a tourniquet was placed in flexion and was released after bone cement hardening. During surgery, cocktail analgesic injection] was injected into the articular capsule, suprapatellar bursa and infrapatellar fat pad. In the extension group, the wound closure was performed in full extension without a drain. In the flexion group, during flexion the articular capsule was marked and incised, which facilitated the accurate closure soft tissue during suturing. In the $90^{\circ}$ flexion, the articular capsule, soft tissue and skin were enclosed without drain (figure 1,2).

The two groups were treated with the same postoperative rehabilitation protocol. At $2^{\text {nd }}$ post op day, 6 weeks and 3 months postoperatively, the ROM, VAS pain score of the anterior knee and KSS were assessed, as well as the knee extension lag and other complications were noted using a Proforma (annexure 1).

Statistical analysis: Data were expressed as mean \pm standard deviation. Statistical analysis was performed using SPSS version 16.0. Moreover, t-test used to analyse the measurement data and enumeration data, respectively. $P<0.05$ was considered statistically significant.

\section{Results}

Table 1: Total number of patients divided into two groups

\begin{tabular}{|c|c|c|}
\hline & Extension Group & Flexion Group \\
\hline Randomization & 33 & 33 \\
\hline $6^{\text {th }}$ Week Follow Up & 34 & 32 \\
\hline $3^{\text {rd }}$ Month Follow Up & 34 & 32 \\
\hline
\end{tabular}

One patient randomised to flexion group underwent wound closure in extension as the joint was found to be lax on table. Age, Gender distribution and BMI of study groups $($ Mean \pm SD)

Table 2: Age, Gender, BMI distribution of patients

\begin{tabular}{|c|c|c|c|}
\hline Group & age & gender(f/m) & bmi \\
\hline Extension $(\mathrm{N}=34)$ & $63.82 \pm 8.69$ & $19 / 15$ & $27.24 \pm 3.70$ \\
\hline Flexion $(\mathrm{N}=32)$ & $64.71 \pm 9.00$ & $21 / 11$ & $27.98 \pm 4.31$ \\
\hline
\end{tabular}

In Extension group 19 of 34 (55.9\%) where females and in Flexion group 21 of $32(65.6 \%)$ where females. In Extension group 8 of $34(23.5 \%)$ and in Flexion group 10 of 32 (31.2\%) patients has a BMI $>30$

Pre-operative assessment of study groups (MeanS $\pm \mathrm{D})$

Table 3: Preop ROM, VAS, KSS scores in two groups

\begin{tabular}{|c|c|c|c|}
\hline Group & $\begin{array}{c}\text { Pre Op Rom } \\
(\mathbf{d e g})\end{array}$ & VAS & KSS \\
\hline Extension $(\mathrm{N}=34)$ & $103.8 \pm 7.98$ & $7.17 \pm 0.13$ & $92.2941 \pm 2.08$ \\
\hline Flexion $(\mathrm{N}=32)$ & $105.6 \pm 8.11$ & $7.13 \pm 0.12$ & $96.2147 \pm 1.72$ \\
\hline
\end{tabular}

Pre operative assessment included pre op range of motion, VAS and knee society score. In extension group mean Pre op Rom was $103.8 \mathrm{deg}$, mean VAS was 7.17 and mean KSS was 92.2(knee assessment-47.1,functional KSS-45.3). While in flexion group mean Pre op ROM was 105.6 deg, mean VAS was 7.13 and mean KSS was 96.21 (KNEE ASSESS-47.7, functional-48.1)

Assessment of study groups at 2 nd POD, 6 th wk and after 3 months (Mean \pm SD) 
Table 4: VAS and ROM in post-op follow up

\begin{tabular}{|c|c|c|c|c|c|c|c|c|c|}
\hline & \multicolumn{3}{|c|}{ VAS } & \multicolumn{3}{c|}{ ROM } & \multicolumn{3}{c|}{ KSS } \\
\cline { 2 - 10 } & $\mathbf{2}^{\text {nd }} \mathbf{P O D}$ & $\mathbf{6}^{\text {th }} \mathbf{W K}$ & $\mathbf{3}^{\text {rd }}$ MON & $\mathbf{2}^{\text {nd }} \mathbf{P O D}$ & $\mathbf{6}^{\text {th }} \mathbf{W K}$ & $\mathbf{3}^{\text {rd }}$ MON & $\mathbf{2}^{\text {nd }} \mathbf{P O D}$ & $\mathbf{6}^{\text {th }} \mathbf{W K}$ & $\mathbf{3}^{\text {rd }} \mathbf{M O N}$ \\
\hline Extension & $7.85 \pm 0.55$ & $3.88 \pm 0.72$ & $3.26 \pm 0.511$ & $55.73 \pm 10.38$ & $87.29 \pm 4.78$ & $100.15 \pm 3.98$ & $69.02 \pm 4.27$ & $110.12 \pm 4.31$ & $169.35 \pm 3.16$ \\
\hline Flexion & $7.81 \pm 0.69$ & $3.40 \pm 0.49$ & $2.93 \pm 0.07$ & $56.59 \pm 9.35$ & $95.78 \pm 5.25$ & $110.31 \pm 3.68$ & $69.28 \pm 4.58$ & $112.7 \pm 4.86$ & $173.16 \pm 3.12$ \\
\hline Paired t & 0.177 & 3.09 & 2.74 & 1.09 & -6.58 & -10.70 & -0.23 & -1.84 & -4.22 \\
\hline$P$ value & 0.860 & 0.004 & 0.010 & 0.284 & 0.001 & 0.001 & 0.810 & 0.074 & 0.000 \\
\hline
\end{tabular}

In post op evaluation VAS for anterior knee at $6^{\text {th }}$ wk follow up was found to be statistically significant (p-0.004) in favour of flexion group but at 3 month follow up the difference was not found to be statistically significant (p- 0.010).In post op ROM evaluation between two groups showed higher ROM at $6^{\text {th }}$ wk and $3^{\text {rd }}$ month which was statistically significant with p-0.001 and 0.001 respectively. Knee society score was found to be statistically significant only at $3^{\text {rd }}$ month follow up between the groups, with better score in flexion group.

The post op follow up evaluation again was categorised based on BMI and the evaluation parameters between the flexion and extension group were tabulated.

Anterior knee pain using VAS at $6^{\text {th }}$ week and $3^{\text {rd }}$ month follow up according to BMI categorisation of study group

Table 5: VAS at 6th works, 3rd month in both groups

\begin{tabular}{|c|c|c|c|c|c|}
\hline \multicolumn{2}{|c|}{} & $\begin{array}{c}\mathbf{6}^{\text {th }} \text { wk } \\
\text { VAS }\end{array}$ & $\begin{array}{c}\boldsymbol{P} \\
\text { value }\end{array}$ & $\begin{array}{c}3^{\text {rd }} \text { MON } \\
\text { VAS }\end{array}$ & $\begin{array}{c}\boldsymbol{P} \\
\text { value }\end{array}$ \\
\hline \multirow{2}{*}{$\begin{array}{c}\text { BMI } \\
<30\end{array}$} & Extension & $3.77 \pm 0.75$ & \multirow{2}{*}{0.069} & $3.22 \pm 0.42$ & \multirow{2}{*}{0.030} \\
\cline { 2 - 3 } $\begin{array}{c}\text { BMI } \\
>30\end{array}$ & Flexion & $3.45 \pm 0.51$ & & $2.95 \pm 0.48$ & \\
\cline { 2 - 3 } & Extension & $4.12 \pm 0.64$ & \multirow{2}{*}{0.041} & $3.25 \pm 0.71$ & \multirow{2}{*}{0.197} \\
& & & $2.87 \pm 0.35$ & \\
\hline
\end{tabular}

This evaluation showed that anterior knee pain using VAS did not show any clinical significant difference between the two groups even with BMI categorisation as $\mathrm{BMI}<30$ and $\mathrm{BMI}$ $>30$.

Range of Motion at 6th week and 3rd month follow up according to BMI categorisation of study groups

Table 6: Range of Motion at 6th week and 3rd month follow up according to BMI categorisation of study groups

\begin{tabular}{|c|c|c|c|c|c|}
\hline \multicolumn{2}{|c|}{} & $6^{\text {TH }}$ WK & $\begin{array}{c}P \\
\text { Value }\end{array}$ & $\begin{array}{c}3^{\text {RD }} \\
\text { MON }\end{array}$ & $\begin{array}{c}\text { P } \\
\text { Value }\end{array}$ \\
\hline \multirow{2}{*}{$\begin{array}{c}\text { BMI } \\
<30\end{array}$} & Extension & $92.5 \pm 2.1$ & \multirow{2}{*}{0.420} & $101.3 \pm 4.1$ & \multirow{2}{*}{0.001} \\
\cline { 2 - 3 } & Flexion & $96.4 \pm 5.6$ & & $111.8 \pm 3.6$ & \\
\hline \multirow{2}{*}{$\begin{array}{c}\text { BMI } \\
>30\end{array}$} & Extension & $86.3 \pm 4.9$ & \multirow{2}{*}{0.003} & $99.37 \pm 4.1$ & \multirow{2}{*}{0.002} \\
\cline { 2 - 3 } & Flexion & $94.3 \pm 4.17$ & & $108.7 \pm 2.3$ & \\
\hline
\end{tabular}

Range of motion during $6^{\text {th }}$ week follow up showed clinical significance $(\mathrm{p}-0.005)$ in patients in both groups with BMI>30.At $6^{\text {th }}$ week and $3^{\text {rd }}$ month follow up ROM showed clinical significance in study population of both groups with patients both with $\mathrm{BMI}<30$ and $\mathrm{BMI}>30$.

Knee Society Score in the study group at $6^{\text {th }}$ week and $3^{\text {rd }}$ month follow up according to BMI categorisation of study group

Table 7: Knee Society Score in the study group at $6^{\text {th }}$ week and $3^{\text {rd }}$ month follow up according to BMI categorisation of study group

\begin{tabular}{|l|c|c|c|c|}
\hline \multicolumn{2}{|c|}{} & $6^{\text {th }}$ week & $3^{\text {rd }}$ Month & P value \\
\hline \multirow{2}{*}{ BMI $<30$} & Extension & $110.5 \pm 4.96$ & $169.7 \pm 3.39$ & \multirow{2}{*}{0.079} \\
\cline { 2 - 5 } & Flexion & $112.6 \pm 4.63$ & $173.2 \pm 4.04$ & \\
\hline \multirow{2}{*}{ BMI >30 } & Extension & $110.2 \pm 2.43$ & $168.5 \pm 3.25$ & \multirow{2}{*}{0.129} \\
\cline { 2 - 4 } & Flexion & $114.1 \pm 5.64$ & $171.8 \pm 2.64$ & \\
\hline
\end{tabular}

Knee society score showed no clinical significance between the extension, flexion groups after categorisation based on BMI.

\section{Discussion}

Anterior knee pain after TKA is currently a major problem. Previous studies reported that anterior knee pain is associated with different factors, including patient factors (pain threshold, preoperative activity and obesity), degree of patellar cartilage damage and wear, prosthesis factors (anatomy and non-anatomical design, rotating and stationary platform), surgery technique (extremely high joint line, patella thickness and height, patellar resurfacing and soft tissue treatment), postoperative pain management etc ${ }^{7,8}$. The position of knee closure here in the study showed clinically significant difference in both flexion and extension groups with study population in flexion group experiencing less anterior knee pain at $6^{\text {th }}$ week and $3^{\text {rd }}$ month follow up irrespective of their BMI.

The factors affecting ROM recovery after TKA mainly include patient selection, prosthesis design, surgical technique, postoperative rehabilitation, pain management and wound healing. Correct wound treatment canreduce tissue adhesion and promote ROM increase. The tension of the wound soft tissue may effect the Knee ROM and pain. The results in this study showed that ROM in the flexion group are significantly higher than those in the extension group, respectively. When BMI was considered this difference persisted between the study groups at $3^{\text {rd }}$ month follow up.

Knee society score which takes into account the physical parameters and functional parameters in this study showed clinically significant improvement in flexion group study group at $3^{\text {rd }}$ month follow up, though at $6^{\text {th }}$ week follow up it was found to be not significant.

In study by Emerson JH et al. ${ }^{[9]}$ of 108 patients At all follow up intervals, the flexion measurements were significantly better in the flexion closure group. At 1 year, the flexion group had 117.9 degrees and the extension group had 112.9 degrees flexion.

In study by Siqun wang et al. ${ }^{[101]}$ which included 80 primary total knee arthroplasties due to osteoarthritis. At 6 weeks and 3 months postoperatively, the ROM in flexion group was $98.95 \pm 10.33^{\circ}$ and $110.05 \pm 4.93^{\circ}$ respectively, with $87.62 \pm$ $8.92^{\circ}$ and $95.62 \pm 6.51^{\circ}$ in extension group, respectively; The VAS score of anterior knee pain in flexion group was $2.02 \pm$ 1.38 and $2.21 \pm 0.87$, respectively, with $2.57 \pm 1.07$ and 2.87 \pm 0.83 in extension group, respectively, which are comparable to current study. The ROM and VAS pain score of the two groups were significantly different at $6^{\text {th }}$ week and $3^{\text {rd }}$ month follow up, with no significant difference at 6 months postoperatively. Concluding that marking the articular capsule incision, wound closure in flexion and high flexion after wound closure can effectively decrease anterior knee pain after TKA and promote the early recovery of ROM.

In a study by Marsi et al. ${ }^{[11]}$, a randomized prospective study of 75 total knee replacements in 64 patients who were randomized to capsular closure with the knee in full extension 
or in flexion was done. The study concluded that the degree of knee flexion at the time of capsular closure in total knee replacement has no effect on early rehabilitation after total knee replacement.

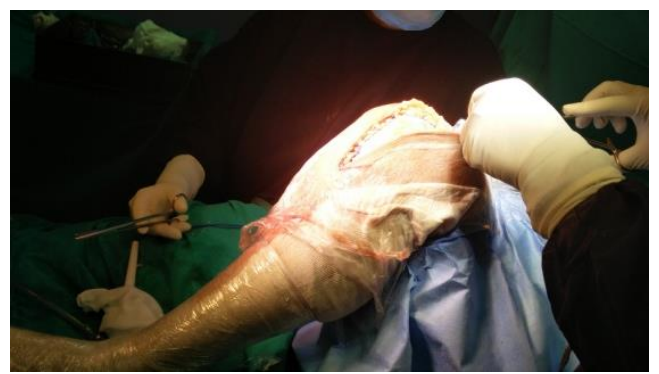

Fig 1: Wound closure in flexion

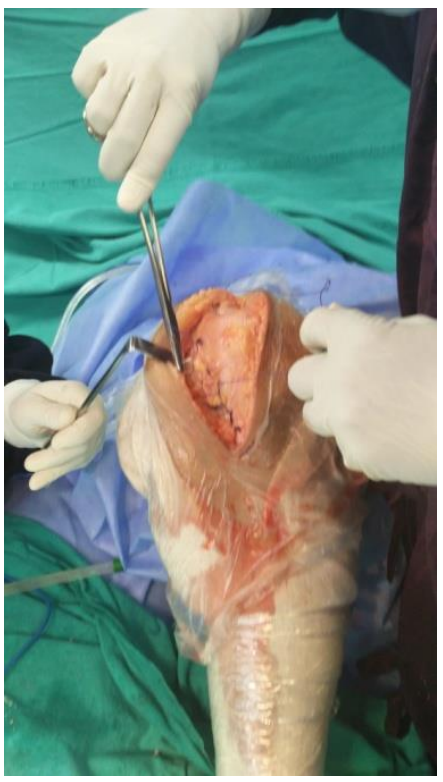

Fig 2: Closure of capsule in flexion

Proforma (Annexure 1)

- Name-

- Age- Sex-

- Height- Weight- Bmi-

- Diagnosis-

- $\quad$ Surgery- Date Of Surgery-

- Group-

- Pre-Op Evaluation-

Rom-

Varus/Valgus-

Ffd-

Vas Score-

Knee Society Score-

Post Op Evaluation-

Post op evaluation in two groups

\begin{tabular}{|c|c|l|l|}
\hline \multicolumn{2}{|c|}{} & Extension Group & Flexion Group \\
\hline \multirow{4}{*}{ Rom } & $2^{\text {nd }}$ POD & & \\
\cline { 2 - 4 } & $6 \mathrm{WKS}$ & & \\
\cline { 2 - 4 } & $3 \mathrm{MON}$ & & \\
\hline \multirow{3}{*}{ Vas } & 2 nd POD & & \\
\cline { 2 - 4 } & $6 \mathrm{WKS}$ & & \\
\hline & $3 \mathrm{MON}$ & & \\
\hline \multirow{3}{*}{ Kss } & $2 \mathrm{nd} \mathrm{POD}$ & & \\
\cline { 2 - 4 } & $6 \mathrm{WKS}$ & & \\
\cline { 2 - 4 } & $3 \mathrm{MON}$ & & \\
\hline
\end{tabular}

Complications-

\section{Conclusion}

The knee position during wound closure after TKA is not only critical but also very important for postoperative knee function recovery. Wound closure in flexion can effectively decrease anterior knee pain after TKA and promote the early recovery of ROM. This difference is more pronounced in patients with $\mathrm{BMI}>30$.Furher study has to be done for $6^{\text {th }}$ month and 1 yr follow up evaluation to see whether these differences will persist.

\section{Reference}

1. Popovic N, Lemaire R. Anterior knee pain with a posterior-stabilized mobile-bearing knee prosthesis: the effect of femoral component design. J Arthroplasty. 2003; 18:396-400.

2. Burnett RS, Boone JL, Rosenzweig SD, Steger-May K, Barrack RL. Patellar resurfacing compared with non resurfacing in total knee arthroplasty: a concise follow-up of a randomized trial. J Bone Joint Surg Am 2009; 91A:2562-2567.

3. Salmon P, Hall GM, Peerbhoy D, Shenkin A, Parker C. Recovery from hip and knee arthroplasty: patients' perspective on pain, function, quality of life, and wellbeing up to 6 months postoperatively. Arch Phys Med Rehabil 2001; 82:360-366.

4. King TV, Kish G, Eberhart RE, Holzaepfel JL. The genuflex skin closure for total knee arthroplasty. Orthopedics. 1992; 15:1057-1058.

5. Smith TO, Davies L, Hing CB. Wound closure in flexion versus extension following total knee arthroplasty: a systematic review. Acta Orthop Belg. 2010; 76:298-306.

6. King TV, Kish G, Eberhart RE, Holzaepfel JL. The 'genuflex' skin closure for total knee arthroplasty. Orthopedics. 1992; 15:1057-1058.

7. Breugem SJ, Sierevelt IN, Schafroth MU, Blankevoort L, Schaap GR, van Dijk CN. Less anterior knee pain with a mobile-bearing prosthesis compared with a fixed-bearing prosthesis. Clin Orthop. 2008; 466:1959-1965.

8. Lehner B, Koeck FX, Capellino S, Schubert TE, Hofbauer R, Straub RH. Preponderance of sensory versus sympathetic nerve fibres and increased cellularity in the infrapatellar fat pad in anterior knee pain patients after primary arthroplasty. J Orthop Res 2008, 26:342-350.

9. Emerson RH Jr, Ayers C, Higgins LL. Surgical closing in total knee arthroplasty. A series follow up. Clin Orthop Relat Res 1999; 368:176-181.

10. Wang et al. Effect of the knee position duringwound closure after total knee arthroplasty on early knee function recovery. Journal of Orthopaedic Surgery and Research. 2014; 9:79.

11. Masri BA, Laskin RS, Windsor RE, Haas SB. Knee closure in total knee replacement: a randomized prospective trial. Clin Orthop. 1996; 331:81-86. 